\author{
Marquette University \\ e-Publications@Marquette
}

$12-2005$

\title{
Combined X-ray diffraction and diffuse reflectance analysis of nanocrystalline mixed Sn(II) and Sn(IV) Oxide Powders
}

Hongmei Deng

Marquette University

Jeanne Hossenlopp

Marquette University, jeanne.hossenlopp@marquette.edu

Follow this and additional works at: https://epublications.marquette.edu/chem_fac

Part of the Chemistry Commons

\section{Recommended Citation}

Deng, Hongmei and Hossenlopp, Jeanne, "Combined X-ray diffraction and diffuse reflectance analysis of nanocrystalline mixed Sn(II) and Sn(IV) Oxide Powders" (2005). Chemistry Faculty Research and Publications. 180.

https://epublications.marquette.edu/chem_fac/180 
NOT THE PUBLISHED VERSION; this is the author's final, peer-reviewed manuscript. The published version may be accessed by following the link in the citation at the bottom of the page.

\title{
Combined X-ray Diffraction and Diffuse Reflectance Analysis of Nanocrystalline Mixed Sn(II) and Sn(IV) Oxide Powders
}

\author{
Hongmei Deng \\ Department of Chemistry, Marquette University, \\ Milwaukee, WI \\ Jeanne M. Hossenlopp \\ Department of Chemistry, Marquette University, \\ Milwaukee, WI
}

\begin{abstract}
Nanocrystalline mixtures of Sn(II) and Sn(IV) oxide powders, potential gas sensor materials, are synthesized via a simple precipitation route using $\mathrm{SnCl}_{2}$ as the precursor. Materials are characterized by powder $\mathrm{X}$ ray diffraction, thermogravimetric analysis, UV-visible diffuse reflectance spectroscopy (DRS), and Fourier transform infrared spectroscopy. The ratio of $\mathrm{Sn}$ (II)/Sn(IV) in powders precipitated at room temperature, as well as the identity of the primary $\mathrm{Sn}(\mathrm{II})$ product ( $\mathrm{SnO}$ or $\left.\mathrm{Sn}_{6} \mathrm{O}_{4}(\mathrm{OH})_{4}\right)$, can be varied by adjusting aging time and washing procedures. The identity of the initial Sn(II) product influences the subsequent phase composition and degree of disorder in the tetragonal $\mathrm{SnO}_{2}$ phase obtained following sintering in air. Analysis of the DRS absorption edge and long-wavelength (Urbach) absorption tail is
\end{abstract}


used to determine the $\mathrm{SnO}_{2}$ optical band gap and extent of disorder. $\mathrm{SnO}_{2}$ obtained by heating the $\mathrm{SnO} / \mathrm{SnO}_{2}$ mixture at 600 or $800{ }^{\circ} \mathrm{C}$ has a smaller optical band gap and a broader Urbach tail than the analogous sample obtained from heating $\mathrm{Sn}_{6} \mathrm{O}_{4}(\mathrm{OH})_{4}$, indicating a more disordered material.

\section{Introduction}

Tin dioxide is an n-type wide band gap semiconductor $\left(E_{\mathrm{g}}=\right.$ 3.6 3.97 eV) $)^{1-3}$ and its electrical properties critically depend on its stoichiometry with respect to oxygen, on the nature and the amount of impurities or dopants present, and on its nanostructure. Tin oxidebased materials have been extensively studied $\frac{4-6}{6}$ because of their unique optical and electrical properties, and thus they have many potential and demonstrated applications, such as in solar energy conversion, $\underline{\underline{7}}$ catalysis, $\underline{\underline{8}}$ gas sensing, $\underline{\underline{9}}$ antistatic coating, $\underline{\underline{10}}$ and transparent electrode preparation. $\frac{11}{1}$ The gas sensing application of tin oxide is based on the change of the material resistance when exposed to different atmospheres, which is due to the charge carrier exchange between the adsorbed gas and the oxide surface. $\frac{12}{\text { Sensitivity has }}$ been shown to be enhanced when the $\mathrm{SnO}_{2}$ grain diameter is on the order of the thickness of the charge depletion layer, approximately 6 $\mathrm{nm} \cdot \underline{13,14}$

Commercially available sensors based on $\mathrm{SnO}_{2}$ pressed powders or thick films are usually sintered at $700{ }^{\circ} \mathrm{C}$ or higher in order to obtain sufficient mechanical strength. However, the average diameter of $\mathrm{SnO}_{2}$ crystallites increases almost linearly with increasing calcination temperature when tin oxide powders are prepared from $\mathrm{SnCl}_{4}$ by sol-gel methods, 15,16 leading to a potential decrease in sensor sensitivity. The use of certain metal oxide additives can significantly suppress the increase of the grain size of $\mathrm{SnO}_{2}, \underline{16,17}$ including the oxides of $\mathrm{Sm}, \mathrm{Ba}, \mathrm{P}, \mathrm{Mo}, \mathrm{W}, \mathrm{Ca}, \mathrm{Sr}, \mathrm{Cr}$, and In. In addition, the addition of catalytic metals, such as $\mathrm{W}, \underline{18} \mathrm{Mo}, \underline{19} \mathrm{Pd}, \underline{\underline{20}}$ and $\mathrm{Sb} \underline{\underline{21}}$ also has been demonstrated to increase the sensitivity and/or selectivity toward specific gases.

Tin/oxygen stoichiometry has also been suggested to influence sensor response, particularly in the case of mixed $\mathrm{SnO} / \mathrm{SnO}_{2}$ materials. This combination has been shown to enhance sensor sensitivity, attributed to the presence of $p-n$ junctions due to having the $p$-type 
$\mathrm{SnO}$ semiconductor mixed with n-type $\mathrm{SnO}_{2} \cdot \underline{22}$ Similar behavior has also been noted in the case of mixtures of $\mathrm{p}$-type CuO with $\mathrm{n}$-type $\mathrm{SnO}_{2} \cdot \frac{23}{}$ Although there has been little work reported on systematic efforts to synthesize and optimize $\mathrm{SnO} / \mathrm{SnO}_{2}$ for potential sensor applications, our previous study $\underline{24}$ has shown that nanocrystalline mixed Sn(II)/Sn(IV) oxide powders can easily be synthesized from $\mathrm{SnCl}_{2}$ precursor by a modified sol-gel technique.

Characterization of the optical band gaps of $\mathrm{SnO}_{2}$-based material is important for sensor applications based on monitoring electrical properties. Typically the absorption edge of a spectrum $a(v)$ versus photon energy $h v$ can be fit to a power law relationship

$$
a(v)=\frac{B\left(h v-E_{Q}\right)^{n}}{h v}
$$

where $B$ is a constant, $E_{g}$ is the optical band gap, and $n$ is an integer or half-integer value that depends on the model used for the electronic transition. For $\mathrm{SnO}_{2}$, the absorption edges are commonly fit $\frac{25,26}{20}$ direct allowed transitions, where $n=1 / 2, \underline{27}$ and indirect forbidden transitions, modeled with $n=2, \underline{28}$ although other power law dependences have also been reported. $\underline{29,30}$ Examination of optical or electrical properties of $\mathrm{SnO}_{2}$ and doped $\mathrm{SnO}_{2}$ powders and films generated by sol-gel techniques, $\underline{31}$ chemical spray deposition, $\underline{32}$ rf sputtering, $\underline{33}$ and dc sputtering $\underline{34}$ has been reported, primarily focusing on the change of band gap energies of $\mathrm{SnO}_{2}$ with changes in annealing temperature and the introduction of dopants. The change in optical reflectance at $620 \mathrm{~nm}$, a measure of reduction of $\mathrm{SnO}_{2}$ nanoparticles in zeolite ${ }^{35}$ and in $\mathrm{Si}-\mathrm{MCM}-41^{36}$ to $\mathrm{SnO}$, has also been reported as a sensing method for detection of $\mathrm{CO}$. However, a detailed analysis of the optical spectroscopy of mixed $\mathrm{SnO} / \mathrm{SnO}_{2}$ materials has not yet been reported.

Optical spectroscopy can also provide insight into the degree of disorder in nanocrystalline materials. At the long-wavelength edge of the absorption band, weak exponential absorbance 37 may also be observed. At a given temperature, this region of the spectrum can be modeled with the empirical Urbach relation $\underline{38,39}$ 
NOT THE PUBLISHED VERSION; this is the author's final, peer-reviewed manuscript. The published version may be accessed by following the link in the citation at the bottom of the page.

$$
\alpha=\alpha_{0} \exp \left(\frac{h v-E_{0}}{E_{\mathrm{u}}}\right)
$$

where $a_{0}$ and $E_{0}$ are material parameters, $h v$ is the photon energy, and $E_{\mathrm{u}}$ is the Urbach energy describing the width of the exponential absorption edge, which originates from the sub-band gap photon

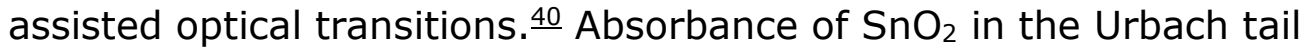
region has been related to electrical responses in gas sensor testing ${ }^{30}$ and the widths of the Urbach tails, $E_{\mathrm{u}}$, have been shown to correlate with degree of crystallinity of $\mathrm{SnO}_{2} \cdot{ }^{29}$

Ultimately, the development and optimization of gas sensors based on mixed $\mathrm{SnO}_{2} / \mathrm{SnO}$ materials requires an understanding of the relationships between synthetic conditions and the formation of tin oxide phases, the effects of the mixed oxidation state on observed phase transitions and thermally induced grain size changes, as well as the characterization of the electrical/optical properties of these materials. The focus of this report is the investigation of mixed oxidation states tin oxide powders generated via a simple precipitation route, including the first detailed optical analysis of this class of potential sensor materials.

\section{Experimental Section}

A $0.1 \mathrm{M} \mathrm{SnCl}_{2}$ (anhydrous $98 \%$, Strem) solution in deionized water was prepared, and $150 \mathrm{~mL}$ of this solution was mixed with 15 $\mathrm{mL}$ of ammonium hydroxide $\left(28 \% \mathrm{NH}_{3}\right.$ in water, reagent grade, Fisher) while stirring at room temperature. Precipitation was observed immediately upon mixing. The mixture was aged in air (open) at room temperature for different times. The ammonia chloride byproduct was removed by repeatedly washing with deionized water, and filtered samples were then allowed to dry at room temperature in air. Samples that were aged for a sufficiently long time so that the solvent evaporated completely were ground with a mortar and pestle to reduce their size before washing. The obtained dried materials were sintered in air for $2 \mathrm{~h}$ at a given temperature in the range $100-800{ }^{\circ} \mathrm{C}$. Commercial $\mathrm{SnO}$ powder (99+\%, Aldrich), $\mathrm{SnO}_{2}$ nanopowder (Aldrich), and $\mathrm{SnO}_{2}$ nanopowder dried from a commercial

Journal of Physical Chemistry B, Vol 109, No. 1 (December 2005): pg. 66-73. DOI. This article is (C) American Chemical Society and permission has been granted for this version to appear in e-Publications@Marquette. American Chemical Society does not grant permission for this article to be further copied/distributed or hosted elsewhere without the express permission from American Chemical Society. 
aqueous colloidal dispersion (15\%, Alfa Aesar) at $70{ }^{\circ} \mathrm{C}$ for $48 \mathrm{~h}$ were used as reference.

X-ray diffraction (XRD) analysis of the powder samples was carried out using a Rigaku diffractometer operated in a parafocusing Bragg-Bretano configuration with a $1 / 2^{\circ}$ divergence slit, $1 / 2^{\circ}$ scatter slit, $0.15-\mathrm{mm}$ receiving slit, and $0.15-\mathrm{mm}$ monochromator receiving slit. The diffractometer uses a focusing graphite monochromator which removes the $\mathrm{Cu} \mathrm{K} \beta$ line but does not reject the $\mathrm{Cu} \mathrm{Ka}$ line. The $\mathrm{Cu}$ source was operated at $1 \mathrm{~kW}$. Data were acquired using a $0.036^{\circ}$ step size in $2 \theta$ and, unless otherwise noted, $20 \mathrm{~s} /$ step integration time. Powder samples were mounted for XRD analysis on microscope slides using 10\% GE 7031 varnish in ethanol. Peak assignments were made using a powder diffraction database. $\underline{41}$ The instrument response was obtained using the National Institute of Standards and Technology (NIST) standard reference material Si powder (SRM 640C). To estimate crystallite sizes and integrated peak intensities, the peaks were fit to pseudo-Voigt functions using XFIT $\underline{42}$ correcting for the instrument response, background signal, and the contribution of the $\mathrm{Cu} \mathrm{Ka}_{2}$ wavelength. Reported uncertainties were obtained by propagating the uncertainties of fit parameters through subsequent calculations.

Elemental analysis was performed using furnace combustion at $1000{ }^{\circ} \mathrm{C}$ and subsequent titration by Midwest Microlab, LLC, to determine the residual chlorine content of the samples as prepared and for selected samples following heat treatment. Thermogravimetric analysis (TGA) was performed on SDT 2960 Simutaneous DTA-TGA Thermogravimeter in air at a scan rate of $20^{\circ} \mathrm{C} / \mathrm{min}$ from $50-1050{ }^{\circ} \mathrm{C}$. Fourier transform infrared (FTIR) spectroscopic analysis was performed at $4 \mathrm{~cm}^{-1}$ resolution on a Nicolet 560 FTIR spectrometer. The samples were mixed in $\mathrm{KBr}$ to make pellets for FTIR analysis.

UV-visible diffuse reflectance spectra (DRS) of powders were recorded on a Shimadzu 265 spectrometer equipped with an IRS-2200 integrating sphere at room temperature in the wavelength region between 220 and $800 \mathrm{~nm}$. Ultrafine $\mathrm{BaSO}_{4}$ powder supplied by Shimadzu Company was used as a reference. 
NOT THE PUBLISHED VERSION; this is the author's final, peer-reviewed manuscript. The published version may be accessed by following the link in the citation at the bottom of the page.

\section{Results and Discussion}

\section{A. Crystalline Phase Characterization and Thermal}

Gravimetric Analysis. Three different aging and washing strategies were attempted. In the case of samples that were aged for a short period of time and where the samples were allowed to dry overnight between washing cycles, the powder was found to be primarily $\mathrm{SnO}_{2}$. Since the focus of this work is on generating mixed oxidation state materials, results from this procedure will not be considered further. The two procedures where polycrystalline Sn(II) species were observed were (a) aging until the solvent completely evaporated prior to washing and (b) shorter aging time (no more than 3 days) followed by washing cycles where the sample was not allowed to dry.

Figure $1 \mathrm{~A}$ shows typical powder XRD patterns for materials originating from synthetic strategy (a) where the solvent was allowed to completely evaporate. The bottom trace in Figure 1A shows data for the as-made material. The expected positions of tetragonal (romarchite) SnO are marked with open triangles, which confirms that the crystalline product is mainly the SnO phase, consistent with the black color of the material. $\frac{43}{}$ Relatively broad, low intensity, peaks of tetragonal (cassiterite) $\mathrm{SnO}_{2}$ phases are also found, indicated by open diamonds. No other crystalline phases are evident; however, the sample contains 3.1 ppt $\mathrm{Cl}$. 
NOT THE PUBLISHED VERSION; this is the author's final, peer-reviewed manuscript. The published version may be accessed by following the link in the citation at the bottom of the page.
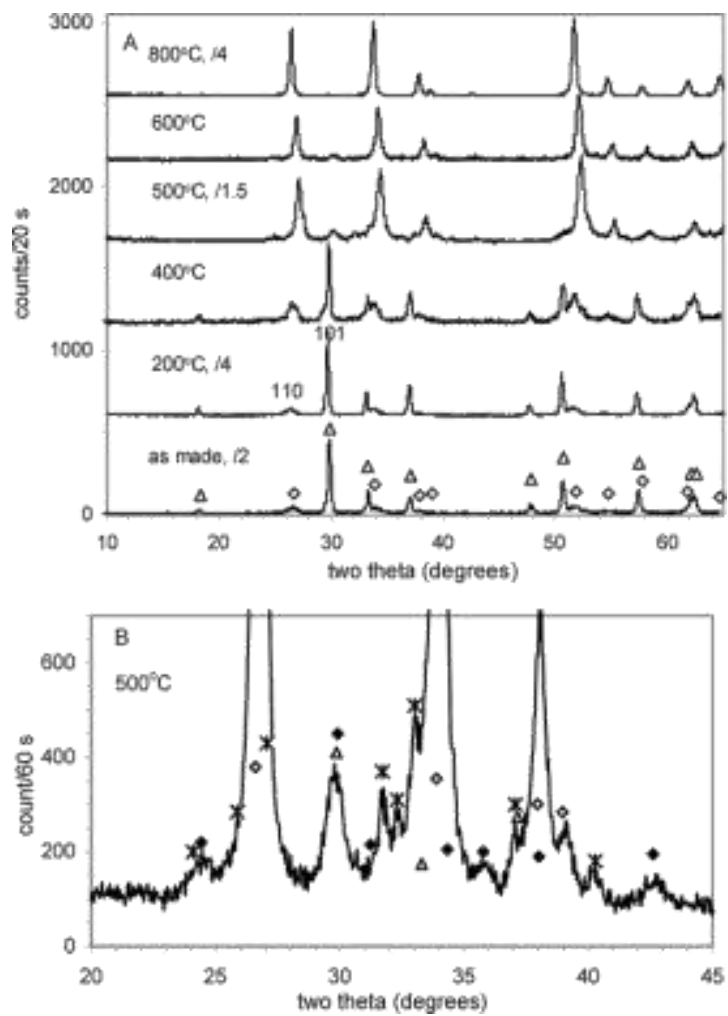

Figure $1(A)$ Powder XRD patterns of material (a) sintered at different temperatures for $2 \mathrm{~h}$. The intensities of some patterns have been scaled as indicated. (B) Expanded scale of the powder XRD pattern of the material heated at $500^{\circ} \mathrm{C}$. Open triangles indicate the peak positions assigned to tetragonal $\mathrm{SnO}$, open diamonds mark tetragonal $\mathrm{SnO}_{2}$ (cassiterite), filled diamonds mark orthorhombic $\mathrm{SnO}_{2}$ and asterisks indicate the intermediate phase $\mathrm{Sn}_{3} \mathrm{O}_{4} . \mathrm{SnO}_{2} 110$ reflection and $\mathrm{SnO} 101$ reflection used to calculate the crystallite sizes are labeled above the peaks.

The mass fraction of polycrystalline $\mathrm{SnO}_{2}$ in the as-prepared material was determined by the method of standard additions. $\frac{44}{4}$ Suppose the sample contains $\mathrm{SnO}_{2}$ and $\mathrm{SnO}$ phases with weight fractions of $X\left(\mathrm{SnO}_{2}\right)$ and $X(\mathrm{SnO})$. The ratio of integrated intensities $(I)$ of two nonoverlapping peaks $\left(\mathrm{SnO}_{2} 110\right.$ reflection and $\mathrm{SnO} 101$ reflection) corresponding to the two phases is given by

$$
\frac{I\left(\mathrm{SnO}_{2}\right)}{I(\mathrm{SnO})}=K \frac{X\left(\mathrm{SnO}_{2}\right)}{X(\mathrm{SnO})}
$$

where $K$ is a constant determined by the structures of the two phases. After adding $Y\left(\mathrm{SnO}_{2}\right)$ grams of the pure phase $\mathrm{SnO}_{2}$, per gram of the original mixture, the ratio of peak intensities becomes 


$$
\begin{aligned}
\frac{I\left(\mathrm{SnO}_{2}\right)}{I(\mathrm{SnO})} & =K \frac{X\left(\mathrm{SnO}_{2}\right)+Y\left(\mathrm{SnO}_{2}\right)}{X(\mathrm{SnO})} \\
& =K^{\prime}\left(X\left(\mathrm{SnO}_{2}\right)+Y\left(\mathrm{SnO}_{2}\right)\right)
\end{aligned}
$$

where $K^{\prime}$ is $K / X(\mathrm{SnO})$. Multiple additions are made to prepare a plot like the one shown in Figure 2, in which the negative $X$ intercept is $X\left(\mathrm{SnO}_{2}\right)$, the concentration of the $\mathrm{SnO}_{2}$ phase in the original sample. Using commercial cassiterite $\mathrm{SnO}_{2}$ nanopowders as the added reference, an estimate that the as-made sample contains approximately $24 \%$ polycrystalline $\mathrm{SnO}_{2}$ is obtained, indicating part of the material has been oxidized to $\mathrm{SnO}_{2}$ in air during the aging and drying process. This is not surprising since small amounts of $\mathrm{SnO}_{2}$ are observed even when the synthesis of $\mathrm{SnO}$ is carried out under $\mathrm{N}_{2} \cdot{ }^{24}$ $I\left(\mathrm{SnO}_{2}\right) / I(\mathrm{SnO})$

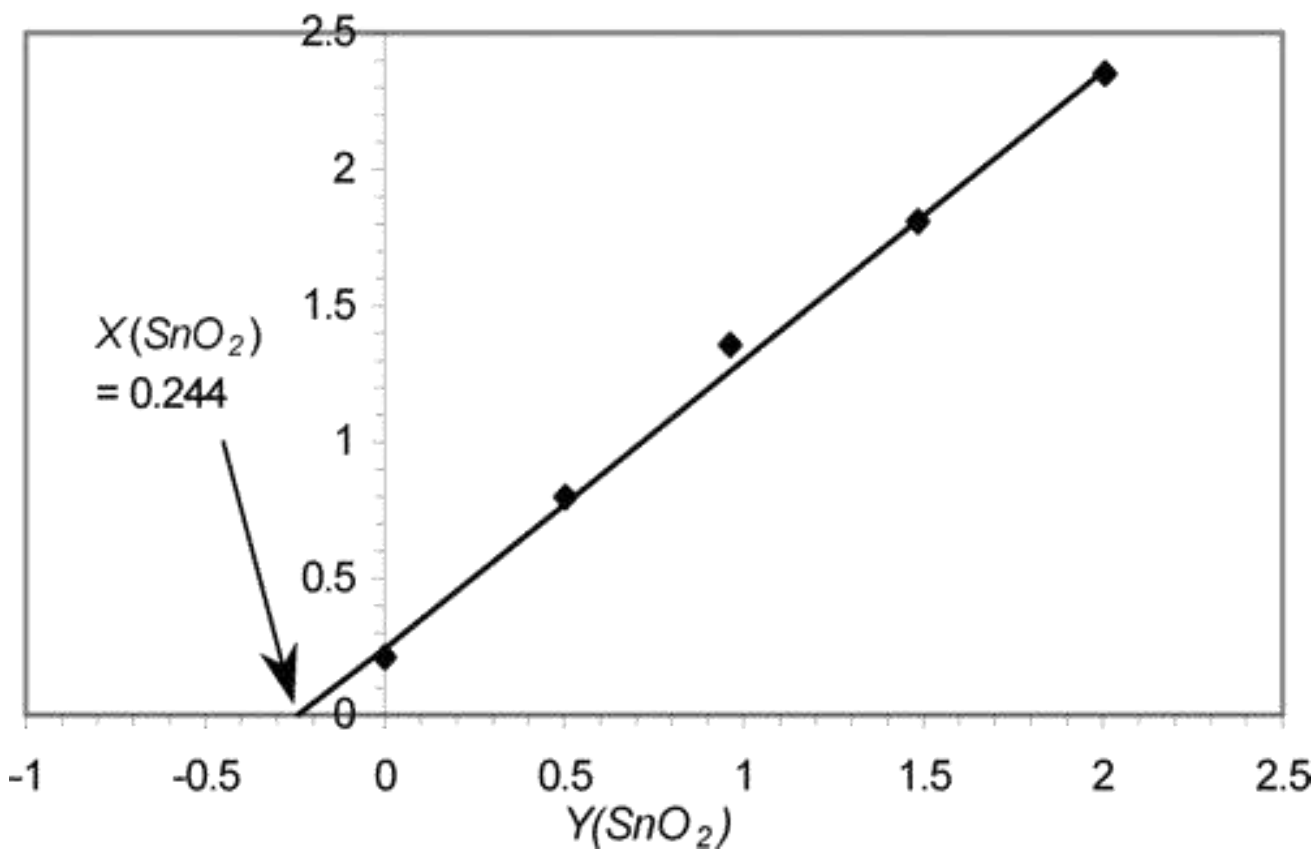

Figure 2 Ratio of the integrated intensity of $\mathrm{SnO}_{2} 110$ reflection to that of $\mathrm{SnO} 101$ reflection as a function of added commercial $\mathrm{SnO}_{2}$ nanopowder. The original sample was material (a).

Average crystallite sizes, $\mathrm{T}$, were determined using the Scherrer equation

$$
\tau=\frac{\kappa \psi}{\beta_{\tau} \cos \theta}
$$

Journal of Physical Chemistry B, Vol 109, No. 1 (December 2005): pg. 66-73. DOI. This article is (C) American Chemical Society and permission has been granted for this version to appear in e-Publications@Marquette. American Chemical Society does not grant permission for this article to be further copied/distributed or hosted elsewhere without the express permission from American Chemical Society. 
where $\mathrm{K}$ is a constant ( 0.9 for powders), ${ }^{44} \beta_{\mathrm{T}}$ is the full width at halfmaximum height of the diffraction peak $\left(\mathrm{SnO}_{2} 110\right.$ reflection and $\mathrm{SnO}$ 101 reflection) of the material after correction for $\mathrm{Cu} \mathrm{Ka}_{2}$ and the instrumental broadening, and $\lambda$ is the X-ray wavelength, 0.1540562 $\mathrm{nm}$ for $\mathrm{Cu} \mathrm{Ka}_{1}$. The powder colors, phase identity and $\mathrm{SnO}$ and $\mathrm{SnO}_{2}$ average crystallite sizes obtained with different sintering temperatures are listed in Table 1.

Table 1: Identification and Average Crystallite Size of Sample (a) and (b) with Different Sintering Temperatures

\begin{tabular}{|c|c|c|c|c|c|}
\hline \multirow{2}{*}{\multicolumn{2}{|c|}{ sample temperature $\left({ }^{\circ} \mathrm{C}\right.$}} & \multirow[b]{2}{*}{ product appearance } & \multirow{2}{*}{ crystalline products } & \multicolumn{2}{|c|}{ crystallite size $(\mathrm{nm})$} \\
\hline & & & & $\mathrm{SnO}$ & $\mathrm{SnO}_{2}$ \\
\hline \multirow[t]{6}{*}{ a } & as made & black & $\mathrm{SnO}, \mathrm{SnO}_{2}$ & $148 \pm 20$ & $11 \pm 1$ \\
\hline & $200^{\circ} \mathrm{C}$ & black & $\mathrm{SnO}, \mathrm{SnO}_{2}$ & $286 \pm 56$ & $12 \pm 1$ \\
\hline & $400^{\circ} \mathrm{C}$ & black & $\mathrm{SnO}, \mathrm{SnO}_{2}$ & $271 \pm 160$ & $13 \pm 1$ \\
\hline & $500^{\circ} \mathrm{C}$ & dark yellow & $\mathrm{SnO}_{2}, \mathrm{SnO}, \mathrm{Sn}_{3} \mathrm{O}_{4}$ & $14 \pm 1$ & $21 \pm 1$ \\
\hline & $600^{\circ} \mathrm{C}$ & yellow & $\mathrm{SnO}_{2}, \mathrm{SnO}$ & $18 \pm 4$ & $49 \pm 6$ \\
\hline & $800^{\circ} \mathrm{C}$ & light yellow & $\mathrm{SnO}_{2}$ & & $74 \pm 5$ \\
\hline \multirow[t]{7}{*}{ b } & as made & yellow & $\mathrm{Sn}_{6} \mathrm{O}_{4}(\mathrm{OH})_{4}$ & & \\
\hline & $100^{\circ} \mathrm{C}$ & yellow & $\mathrm{Sn}_{6} \mathrm{O}_{4}(\mathrm{OH})_{4}$ & & \\
\hline & $200^{\circ} \mathrm{C}$ & $\tan$ & $\mathrm{Sn}_{6} \mathrm{O}_{4}(\mathrm{OH})_{4}, \mathrm{SnO}_{2}$ & & \\
\hline & $300^{\circ} \mathrm{C}$ & dark yellow & $\mathrm{SnO}_{2}$ & & \\
\hline & $400^{\circ} \mathrm{C}$ & dark yellow & $\mathrm{SnO}_{2}$ & & $7.5 \pm 0.4$ \\
\hline & $600^{\circ} \mathrm{C}$ & yellow & $\mathrm{SnO}_{2}$ & & $26 \pm 2$ \\
\hline & $800^{\circ} \mathrm{C}$ & yellow & $\mathrm{SnO}_{2}$ & & $87 \pm 9$ \\
\hline
\end{tabular}

An overview of the phase transitions observed for this material can be obtained by combining the data shown in Figure 1 and Table 1. As determined above, the initial sample contains polycrystalline $\mathrm{SnO}$ and $\mathrm{SnO}_{2}$ in an approximately 3:1 mass ratio. Note that the amount of amorphous material is not assessed via the XRD data. The initial crystallite size of $\mathrm{SnO}$ is significantly larger than that of $\mathrm{SnO}_{2}$. After heating at $200{ }^{\circ} \mathrm{C}, \mathrm{XRD}$ peaks for both phases increase in intensity and the average crystallite size of $\mathrm{SnO}$ nearly doubles while the $\mathrm{SnO}_{2}$ size remains virtually unchanged. The intensities of the $\mathrm{SnO}_{2}$ peaks increase relative to $\mathrm{SnO}$ after heating at $400^{\circ} \mathrm{C}$ with minimal change in size for either species compared to the $200{ }^{\circ} \mathrm{C}$ treatment. The larger uncertainty in SnO crystallite size after heating at $400^{\circ} \mathrm{C}$ is attributed to a larger asymmetric contribution to the peak profile from the broad baseline signal. The oxidation of $\mathrm{SnO}$ to $\mathrm{SnO}_{2}$ becomes evident after heating at $500{ }^{\circ} \mathrm{C}$; the intensities of the $\mathrm{SnO}$ peaks are markedly 
decreased and the average crystallite size decreases from a value of $\sim 270 \mathrm{~nm}$ to $14 \mathrm{~nm}$. SnO is only weakly evident after heating at $600{ }^{\circ} \mathrm{C}$. A corresponding increase in $\mathrm{SnO}_{2}$ intensities and average crystallite sizes are observed over this same temperature range.

Additional weak peaks not assignable to the tetragonal SnO or $\mathrm{SnO}_{2}$ phases are also observed after heating at $500{ }^{\circ} \mathrm{C}$ and these peaks can be seen more clearly in the expanded scale of Figure 1B. The asterisks in Figure 1B mark the expected positions and relative intensities of an intermediate oxide phase, $\mathrm{Sn}_{3} \mathrm{O}_{4} \cdot \underline{45}$ This phase was also observed previously from a modified thermal synthesis in our laboratory ${ }^{24}$ and appears to originate exclusively from $\mathrm{Cl}$-containing precursors. In addition, peaks consistent with the orthorhombic $\mathrm{SnO}_{2}$ phase are also observed; these peaks are labeled with solid diamonds in Figure 1B. The assignment of the metastable orthorhombic phase is tentative at this point; however, we note that its formation in thin films has been related to having a high density of amorphous material. $\underline{46}$

TGA analysis was also performed on this sample and the results are shown in trace (a) of Figure 3 . In the temperature range $50-470{ }^{\circ} \mathrm{C}$, the sample mass decreased, consistent with loss of water. The persistence of water/OH groups associated with metal oxide materials at high temperatures has been noted in other studies. $\frac{47-49}{4}$ Loss of water is attributed primarily to physisorbed molecular water until approximately $200{ }^{\circ} \mathrm{C}$ and above this temperature range to surface hydroxyl group condensation or chemisorbed water. ${ }^{47,48}$ Rutile $\mathrm{SnO}_{2}$ is the thermodynamically stable phase at high temperature. ${ }^{49}$ For comparison, the reference $\mathrm{SnO}_{2}$ nanopowder dried from the commercial aqueous dispersion was analyzed via TGA (trace $c$ in Figure 3). Mass (water) loss from this sample occurred over the entire temperature range. Consistent with the XRD data shown in Figure 1, the TGA analysis of the $\mathrm{SnO} / \mathrm{SnO}_{2}$ sample shows that, between 470 and $670{ }^{\circ} \mathrm{C}$, the sample mass increased by $6 \%$ as SnO was oxidized to $\mathrm{SnO}_{2}$. This suggests that the sample is $\sim 50 \%$ SnO once it has been heated to $470{ }^{\circ} \mathrm{C}$. The temperature dependence of the conversion of $\mathrm{SnO}$ to $\mathrm{SnO}_{2}$ observed here is also consistent with Mössbauer analysis of thermally annealed SnO powders. $\underline{50}$ The ratio of $\mathrm{SnO}$ to $\mathrm{SnO}_{2}$ reduces with temperature, and in addition, we also find the ratio can 
be adjusted by different aging times of mixtures of $\mathrm{SnCl}_{2}$ and aqueous ammonia. $\underline{51}$

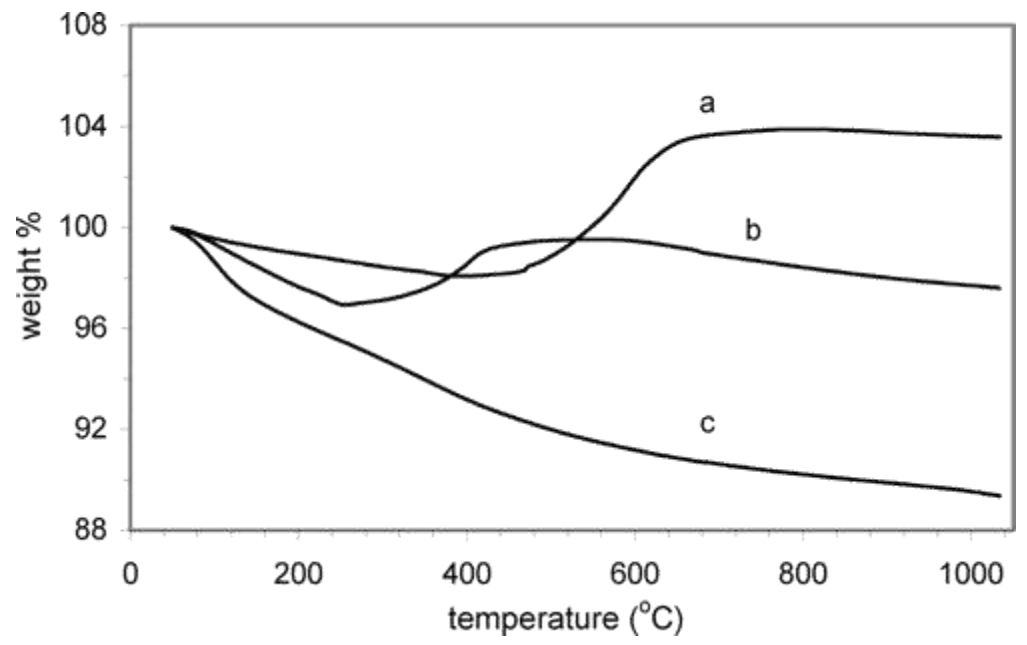

Figure 3 TGA patterns of materials obtained from the mixtures of $\mathrm{SnCl}_{2}$ and aqueous ammonia aged and washing with different strategies. (a) material was aged for enough time to allow the solvent to evaporate completely, (b) material aged for a shorter time and followed by washing cycles where the sample was not allowed to dry, (c) reference powders obtained from a commercial $\mathrm{SnO}_{2}$ aqueous dispersion.

The alternative synthesis/washing strategy (b) where the sample was filtered shortly after mixing the $\mathrm{SnCl}_{2}$ and aqueous ammonia solutions and then washed repeatedly so that the sample was always kept wet during the process of washing, resulted in formation of $\operatorname{tin}(\mathrm{II})$ oxyhydroxide, $\mathrm{Sn}_{6} \mathrm{O}_{4}(\mathrm{OH})_{4}$, a species that readily precipitates from solutions of stannous salts. $\frac{52}{2}$ Figure $4 \mathrm{~A}$ shows the powder XRD analysis of this material, with expected positions and relative intensities of $\mathrm{Sn}_{6} \mathrm{O}_{4}(\mathrm{OH})_{4}$ shown at the bottom. In contrast to our previous report where a mixture of $\mathrm{Sn}_{6} \mathrm{O}_{4}(\mathrm{OH})_{4}$ and tetragonal $\mathrm{SnO}_{2}$ was produced by heating an aqueous $\mathrm{SnCl}_{2}$ solution with a little methanol at $100{ }^{\circ} \mathrm{C}_{1}{ }^{24}$ there is only a minimal amount of $\mathrm{SnO}_{2}$ observed in the expanded trace of Figure 4B. Heating this material at $100^{\circ} \mathrm{C}$ results in further crystallization of tin(II) oxyhydroxide, as evident by the increase in XRD peak intensities. The $\mathrm{SnO}_{2}$ phase begins to become evident after heating at $200^{\circ} \mathrm{C}$ and the tin(II) oxyhydroxide phase has completely disappeared at $400^{\circ} \mathrm{C}$. Powder appearance, phase assignments, and average crystallite sizes of $\mathrm{SnO}_{2}$ are shown in Table 1. After heating at either $400^{\circ} \mathrm{C}$ or $600^{\circ} \mathrm{C}$, the $\mathrm{SnO}_{2}$ crystallite sizes from this sample are significantly smaller than those obtained from the $\mathrm{SnO} / \mathrm{SnO}_{2}$ sample, suggesting a suppression of grain size growth similar to that reported for samples of $\mathrm{SnO}_{2}$ with 
other metal oxide additives. However, heating at $800^{\circ} \mathrm{C}$ results in similar average crystallite sizes. The material can be oxidized as $\mathrm{SnO}_{2}$ after stored in air for long time.
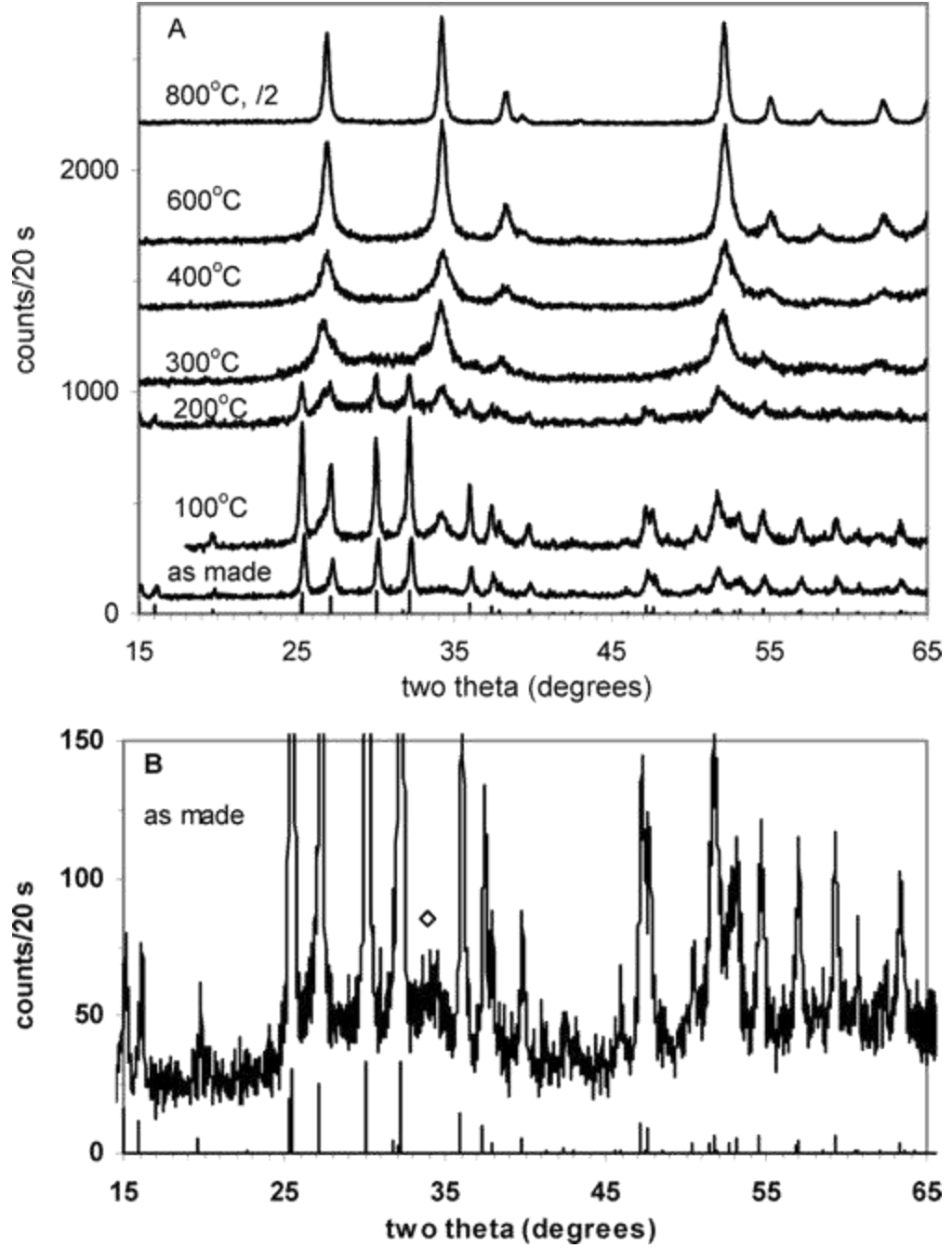

Figure 4 (A) Powder XRD patterns of material $(b)$ as a function of sintering temperature. (B) Expanded scale of XRD pattern of the same material, as-precipitated. Positions and relative intensities of tin(II) oxyhydroxide $\mathrm{Sn}_{6} \mathrm{O}_{4}(\mathrm{OH})_{4}$ are shown below. Open diamonds mark the tetragonal $\mathrm{SnO}_{2}$ phase.

The TGA analysis of $\mathrm{Sn}_{6} \mathrm{O}_{4}(\mathrm{OH})_{4}$ is shown in trace $b$ of Figure 3. There is an initial decrease in mass observed until approximately $260^{\circ} \mathrm{C}$, which is attributed to the loss of water. From 260 to $450^{\circ} \mathrm{C}$, the sample mass increased, presumably due to added mass from oxygen due to the oxidation of tin(II) oxyhydroxide to $\mathrm{SnO}_{2}$. This indicates tin(II) oxyhydroxide phase is not as thermally stable as tetragonal $\mathrm{SnO}$, for the oxidation of the latter from $\mathrm{SnO}$ to $\mathrm{SnO}_{2}$ happened at a higher temperature, near $500^{\circ} \mathrm{C}$. Trace $b$ in Figure 3

Journal of Physical Chemistry B, Vol 109, No. 1 (December 2005): pg. 66-73. DOI. This article is (C) American Chemical Society and permission has been granted for this version to appear in e-Publications@Marquette. American Chemical Society does not grant permission for this article to be further copied/distributed or hosted elsewhere without the express permission from American Chemical Society. 
also shows that, at the temperatures higher than $590^{\circ} \mathrm{C}$, the sample mass decreased again, which is indicative of continuing loss of water over the entire temperature range.

B. Optical Spectroscopy. Diffuse reflectance spectra were measured in order to determine the $\mathrm{SnO}_{2}$ optical band gaps for selected samples. In addition, evaluation of the width sub-band gap exponential absorption (Urbach tails) was performed in order to characterize the degree of crystallinity of the powders. The optical absorption was represented by the Kubelka-Munk (KM) remission function calculated from the DRS spectra ${ }^{31,53-55}$ at constant scattering

$$
F(R)=(1-R)^{2} / 2 R
$$

Figure 5 shows the optical absorption spectra of the material originating from synthetic route (a). In the as-prepared sample, which is the mixture of $\mathrm{SnO}$ and $\mathrm{SnO}_{2}$, there are two absorption peaks, a strong one at $\sim 280 \mathrm{~nm}$ and a broader, weaker feature at $\sim 400 \mathrm{~nm}$. The visible wavelength absorption peak is reduced after heating at $200{ }^{\circ} \mathrm{C}$ and almost completely disappears after heating at $500{ }^{\circ} \mathrm{C}$. This feature is attributed to the tetragonal SnO phase based on the correlation with the temperature dependence of XRD peaks assigned to SnO as shown in Figure 1. The absorbance pattern of commercial SnO powder, also shown in Figure 5, is consistent with this assignment. Our as-made sample contains some $\mathrm{SnO}_{2}$ (Figures 1 and 2); therefore, its absorbance in the visible region is much lower than that of commercial SnO powder. As mentioned above, for direct-band semiconductor, the absorption coefficient $\mathrm{a}$ is related to the excitation energy $\left(E_{\text {exc }}=h v\right.$ ) by eq 1 . Since the absorption coefficient $a$ is proportional to the absorbance $A^{57}$ (represented by $F(R)$ ), the optical band gap of the materials can be obtained by extrapolating the linear portion of $(A h v)^{2}$ versus $h v$ until it intersects the $h v$ axis at $E_{g}$. The obtained direct-band gaps of SnO are 2.12, 2.06, and $2.35 \mathrm{eV}$ (with uncertainties $0.01 \mathrm{eV}$ obtained from 5 repeated experiments and regression analysis) for asmade sample and after being heated at 200 and $400^{\circ} \mathrm{C}$, respectively, close to the reported band gap energy of $\mathrm{SnO}, 2.5-3 \mathrm{eV} .{ }^{50}$ 


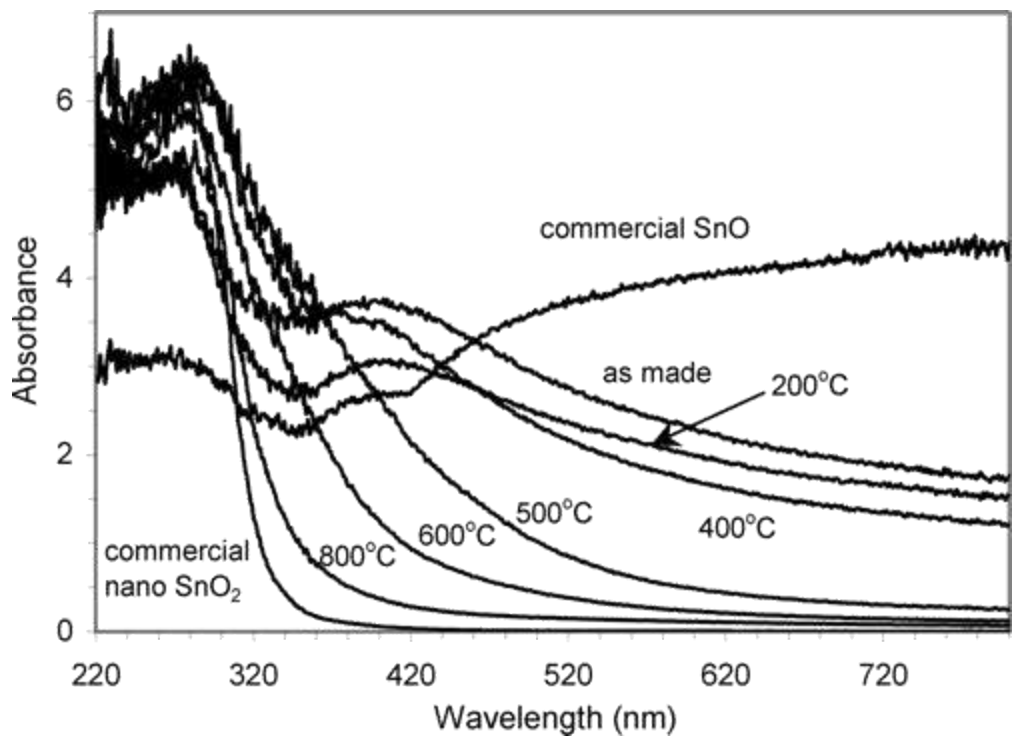

Figure 5 UV-visible diffuse reflectance spectra (DRS) of material (a), sintered at different temperatures for $2 \mathrm{~h}$. The spectra of commercial $\mathrm{SnO}$ and commercial $\mathrm{SnO}_{2}$ nanopowders are also shown.

After heating to temperatures at or above $500^{\circ} \mathrm{C}$, tetragonal $\mathrm{SnO}_{2}$ dominates the sample, and only one obvious absorbance peak, located at $\sim 280 \mathrm{~nm}$, is observed in the DRS data. The absorbance edge increases with increasing annealing temperature. The direct-band gaps of material (a), listed in Table 2, range from 3.4 to $3.8 \mathrm{eV}$, close to the reported band gap energy of $\mathrm{SnO}_{2}, 3.6 \sim 3.97 \mathrm{eV} .^{1-3}$ Since the remission function also depends strongly on particle size for weak absorbers, ${ }^{56}$ the direct-band gaps of nanometer sized powders are often estimated from the plots of absorbance converted from DRS spectra versus wavelength. $31,54,55$ Using this method, band gaps of 2.5 3.6 eV are obtained, smaller than the values obtained from the plots of $(A h v)^{2}$ versus $h v$. However, the trend is the same; the band gap energy of the material increases with annealing temperature, where the crystallite size also increases. This tendency has been reported for other precipitated tin oxides and is attributed to a combination of factors including composition, changes in crystalline size, and surface reconstruction during annealing. $\underline{58}$

Table 2: Width of Urbach Tail and the Band Gap of $\mathrm{SnO}_{2}$ of the Sample (a) and (b) with Different Sintering Temperatures ${ }^{a}$

$$
E_{\mathrm{u}}(\mathrm{eV})
$$

$$
\text { sample temp }\left({ }^{\circ} \mathrm{C}\right) \quad \text { UV range visible range } \lambda \sim A \quad h v \sim(A h v)^{2}
$$

Journal of Physical Chemistry B, Vol 109, No. 1 (December 2005): pg. 66-73. DOI. This article is (C American Chemical Society and permission has been granted for this version to appear in e-Publications@Marquette. American Chemical Society does not grant permission for this article to be further copied/distributed or hosted elsewhere without the express permission from American Chemical Society. 
NOT THE PUBLISHED VERSION; this is the author's final, peer-reviewed manuscript. The published version may be accessed by following the link in the citation at the bottom of the page.

a

b

commercial nano $\mathrm{SnO}_{2}$

$\begin{array}{lll}\text { as-made } & 1.74 & 1.75 \\ 200^{\circ} \mathrm{C} & 1.10 & 1.90 \\ 400^{\circ} \mathrm{C} & 1.25 & 1.37 \\ 500^{\circ} \mathrm{C} & 0.61 & \\ 600^{\circ} \mathrm{C} & 0.61 & \\ 800^{\circ} \mathrm{C} & 0.40 & \\ 400^{\circ} \mathrm{C} & 0.67 & \\ 600^{\circ} \mathrm{C} & 0.44 & \\ 800^{\circ} \mathrm{C} & 0.27 & \\ \text { N.A. } & 0.21 & \\ \end{array}$

2.943 .66

$3.32 \quad 3.77$

3.103 .63

2.513 .42

3.013 .60

3.563 .81

$2.88 \quad 3.39$

3.603 .82

3.723 .91

3.763 .95

a Note: the uncertainty is $\pm 0.01 \mathrm{eV}$.

In comparison, the powder dried at $70^{\circ} \mathrm{C}$ from the commercial $\mathrm{SnO}_{2}$ aqueous dispersion was used as a reference and was subsequently heated at different temperatures for $2 \mathrm{~h}$. In this case, the $\mathrm{SnO}_{2}$ band gap was found to be $3.9 \mathrm{eV}$ in the as-dried material, which had an average crystallite size of $4.74 \mathrm{~nm}$, and the band gap was reduced to $3.6 \mathrm{eV}$ after being heated at $800{ }^{\circ} \mathrm{C}$ to produce 6.74 $\mathrm{nm}$ crystallites (see the Supporting Information), which are consistent with the quantum size effects $\underline{59}$ where the observed band gaps tend to decrease with increasing grain size when the grain size is in the quantum dot size regime ${ }^{56,60,31}$

The observed increase in band gap upon heating may be due to changes in material properties, in particular, the possibility of having a higher amorphous content or more defects and impurities at lower temperatures, which would result in a lower optical band gap, similar to that reported for sol-gel derived $\mathrm{ZrO}_{2}$ materials. $\frac{61}{1}$ The width of the Urbach tail, also known as the Urbach energy, $\underline{62} E_{\mathrm{u}}$, should provide some insight into this possibility. $E_{\mathrm{u}}$ is determined using eq 2 , fitting the linear portion of a plot of In $A$ versus $h v$. After heating the sample prepared via route (a) to a temperature of $500^{\circ} \mathrm{C}$, the Urbach energy is found to be $0.61 \mathrm{eV}$ and the value decreases to $0.40 \mathrm{eV}$ after heating at $800{ }^{\circ} \mathrm{C}$. These values are consistent with observed Urbach energies for amorphous and partially crystalline $\mathrm{SnO}_{2}$ thin films. ${ }^{29}$ In contrast, the absorbance spectrum of commercial nano $\mathrm{SnO}_{2}$ (Figure 5) has sharp peak and a narrow Urbach tail, $E_{\mathrm{u}}=0.21 \mathrm{eV}$, characteristic of a much more ordered structure. Furthermore, the Urbach energy of $\mathrm{SnO}_{2}$ powders dried from commercial aqueous dispersion remains constant at $0.12 \mathrm{eV}$ even after heating to different temperatures. Polycrystalline films of $\mathrm{SnO}_{2}$ have been reported to have 
values in the range of $0.23 \mathrm{eV}$, whereas single crystals of $\mathrm{SnO}_{2}$ have an estimated value of $0.037 \mathrm{eV} .^{29}$

To know whether the residual $\mathrm{Cl}$ affected the optical properties of the materials, two more experiments were performed. First, the elemental analysis was performed on materials heated at 400 and $800{ }^{\circ} \mathrm{C}$, and it was found that the net residual $\mathrm{Cl}$ content had not changed, after the mass change during the heating process was considered. Second, the optical properties for the sample are the same even if the sample was continually repeatedly washed with deionized water to reduce the residual $\mathrm{Cl}$ content as low as possible indicated by no white precipitation in the filtrate with $\mathrm{AgNO}_{3}$ solution as the indicator. These two experiments show that the residual $\mathrm{Cl}$ content in our samples is not the cause of the changes of optical properties of our materials with temperature.

It has been reported ${ }^{49}$ that the presence of a large amount of the hydroxyl groups in the $\mathrm{SnO}_{2}$ crystals can cause significant crystalline deformation by producing a large amount of Sn vacancy sites. This can also change oxygen positions in the $\mathrm{SnO}_{2}$ rutile structure, which will change the symmetry of the representative tin-oxygen octahedron. The crystal deformation reduces with temperature as the number of vacancies decreases with annealing temperature up to approximately $700^{\circ} \mathrm{C}$. Our results are consistent with the materials having a significant degree of amorphous content or defects. The possible contribution of $\mathrm{Sn}_{3} \mathrm{O}_{4}$ and/or orthorhombic $\mathrm{SnO}_{2}$ requires further investigation. We note that preliminary studies of powders enriched in orthorhombic $\mathrm{SnO}_{2}$ suggest that this phase leads to a shift of the absorption edge to lower energies. ${ }^{51}$

Finally, FTIR spectra of the material (a) are shown in Figure 6. The broad absorption peak observed at $\sim 3450 \mathrm{~cm}^{-1}$ is due to $\mathrm{OH}$ stretching modes from molecular water and a weak band due to the water deformation mode at $\sim 1650 \mathrm{~cm}^{-1}$. ${ }^{48}$ The bands at $\sim 636$ and 526 $\mathrm{cm}^{-1}$ for as-made material and at $\sim 656$ and $526 \mathrm{~cm}^{-1}$ for sample heated at $200^{\circ} \mathrm{C}$ are assigned as $\mathrm{Sn}-\mathrm{O}-\mathrm{Sn}$ and $\mathrm{Sn}-\mathrm{O}$ vibrations respectively, $\stackrel{3,63}{ }$ and the latter is from $\mathrm{Sn}-\mathrm{OH}$. The peak positions of the material (a) at low temperatures are more similar to those of commercial nanocrystalline $\mathrm{SnO}_{2}$ powders than of commercial SnO. 
The FTIR data are thus consistent with the XRD, TGA, and DRS analyses that indicate the presence of hydrous mixed $\mathrm{SnO}_{2}$ and $\mathrm{SnO}$ phases in this sample.

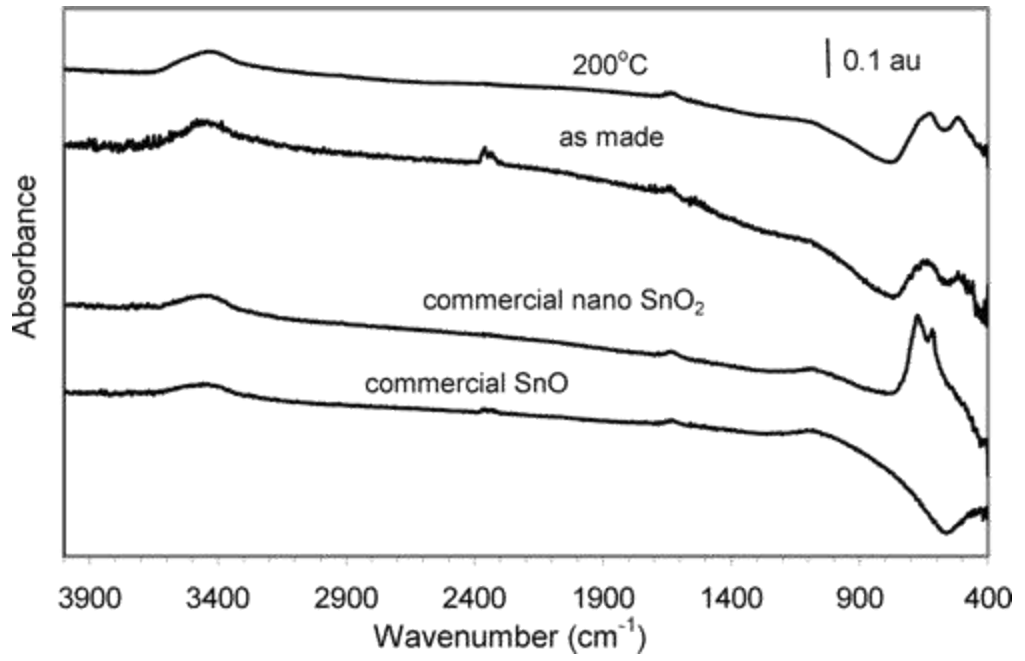

Figure 6 FTIR spectra of material (a) after sintering at different temperatures. The spectra of commercial $\mathrm{SnO}$ and commercial $\mathrm{SnO}_{2}$ nanopowders are also shown.

The DRS data shown in Figure 7 for materials derived from synthetic route (b), initially tin(II) oxyhydroxide, indicate that the sample as-made and after heating at $100^{\circ} \mathrm{C}$ have similar spectra and a sharp absorption peak, at $\sim 300 \mathrm{~nm}$. The sharp absorption onset indicates that these samples have little amorphous content. Upon heating at $200{ }^{\circ} \mathrm{C}$, the absorption band shifts to lower energy and the Urbach tail is broadened. This is consistent with the XRD data in Figure 4 where a broad background, suggesting amorphous or disordered content, is observed during the conversion of tin(II) oxyhydroxide to $\mathrm{SnO}_{2}$. Samples heated in the range $300-400{ }^{\circ} \mathrm{C}$ exhibit a shift of the main absorption band to higher energies with larger Urbach energies. Heating to higher temperatures leads to a reduction in width of the Urbach tail and an increase in the optical band gap energy. Once the sample has been heated at $800^{\circ} \mathrm{C}$, it exhibits an optical band gap of $3.9 \mathrm{eV}$, similar to that of the nanocrystalline commercial reference and, based on $E_{\mathrm{u}}$, is more structurally ordered than that derived from the $\mathrm{SnO} / \mathrm{SnO}_{2}$ mixed material. 


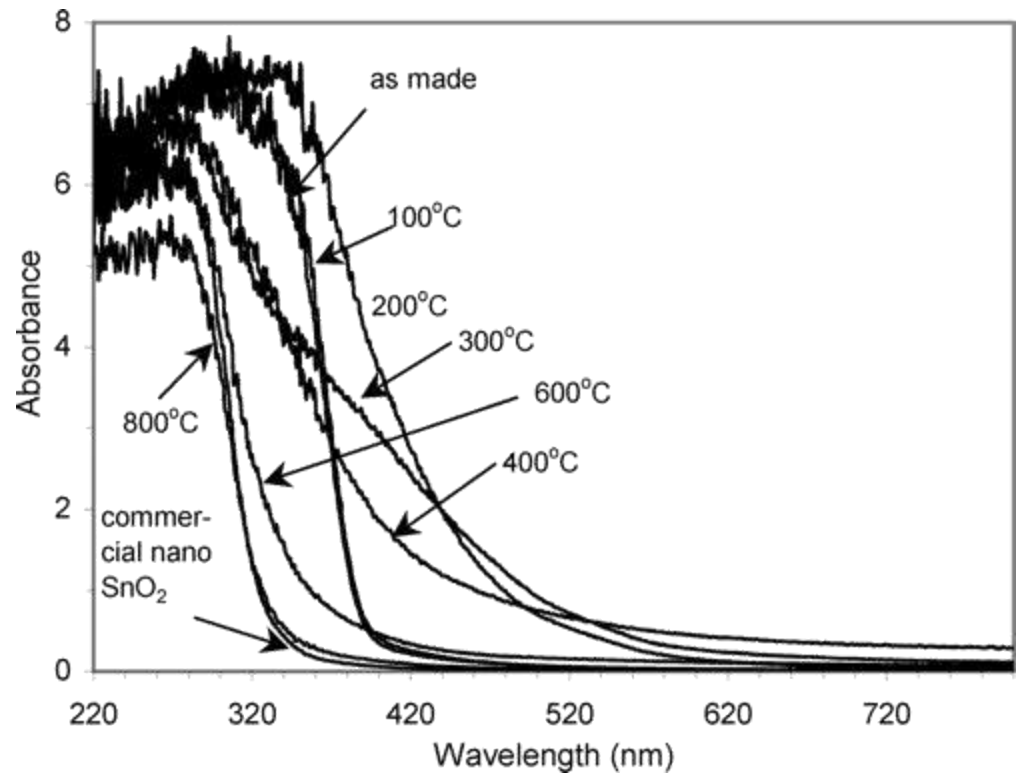

Figure 7 UV-visible diffuse reflectance spectra (DRS) of material (b) after sintering at different temperatures. The spectrum of commercial $\mathrm{SnO}_{2}$ nanopowders is included.

The FTIR spectra of tin(II) oxyhydroxide samples heated at different temperatures are shown in Figure 8. It is noticed that the broad absorption peak observed at $\sim 3450 \mathrm{~cm}^{-1}$, which is due to $\mathrm{OH}$ stretching modes from molecular water, became wider and lower in intensity with increasing annealing temperature but still exists after heating at $600{ }^{\circ} \mathrm{C}$ even after subtracting the effect of water adsorbed in the $\mathrm{KBr}$ pellet, consistent with TGA analysis. After heating at $80{ }^{\circ} \mathrm{C}$, this absorption peak is only weakly present, indicating that the amount of the hydroxyl group is very limited. The band at $\sim 550 \mathrm{~cm}^{-1}$, assigned as a $\mathrm{Sn}-\mathrm{O}$ vibration of $\mathrm{Sn}-\mathrm{OH}$ in the as-made sample, becomes a broad shoulder after heating at $300{ }^{\circ} \mathrm{C}$, whereas the broad band in the range of $\sim 636-698 \mathrm{~cm}^{-1}$ is initially evident as a weak shoulder at low temperature, and then forms a peak after heating at a temperature above $300^{\circ} \mathrm{C}$. The intensity of this feature increases with temperature, consistent with an assignment of a $\mathrm{Sn}-\mathrm{O}-\mathrm{Sn}$ vibration. 


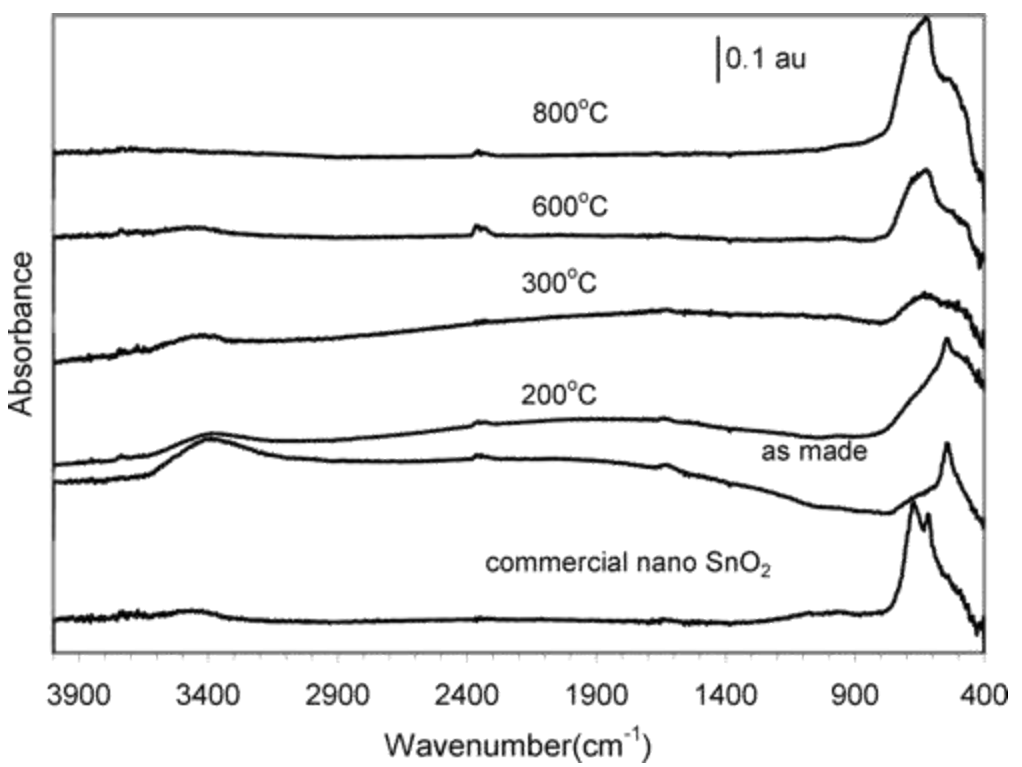

Figure 8 FTIR spectra of material (b) after sintering at different temperatures and the commercial $\mathrm{SnO}_{2}$ nanopowder. Background spectrum of pure $\mathrm{KBr}$ pellet was subtracted from each spectrum.

DRS analysis is thus shown to be an excellent complement to powder XRD measurements, providing insight into the degree of structural disorder. The above results clearly demonstrate that for mixed tin(II)/tin(IV) oxides the subsequent thermally induced evolution of the tin oxide phase content and morphology depends on the identity of the initial Sn(II) oxide phase present. The band gap energies of $\mathrm{SnO}_{2}$ obtained by heating sample (a), the mixture of $\mathrm{SnO} / \mathrm{SnO}_{2}$, are lower than those of materials obtained from sample (b), tin(II) oxyhydroxide, at the same annealing temperature. The former sample also has bigger Urbach energies than the latter, indicating more structural disorder. The presence of a large amount of the hydroxyl groups in the crystals may contribute to the crystalline disorder.

Preliminary results have been obtained using conductivity measurements in thick films of tin oxide powders in polypyrrole. Upon exposure to 500 ppm mixtures of volatile organic vapors in nitrogen, a composite film containing material (a) that had been annealed at $600{ }^{\circ} \mathrm{C}$ exhibited twice the sensitivity to methanol as to ethanol. The same material that had been annealed at $500^{\circ} \mathrm{C}$ exhibited slightly higher sensitivity to ethanol rather than methanol with overall sensitivities lower for this powder than for the material heated at 
$600{ }^{\circ} \mathrm{C}$. Sensors made from material (b), where no SnO was found, exhibited typically lower sensitivities than materials with a small amount of SnO. A detailed analysis of sensor behavior will be published elsewhere. $\underline{64}$

\section{Conclusions}

Nanocrystalline mixed $\mathrm{Sn}(\mathrm{II}) / \mathrm{Sn}(\mathrm{IV})$ oxide powders can be synthesized from $\mathrm{SnCl}_{2}$ by a simple precipitation method. The mixture containing tetragonal $\mathrm{SnO}$ and tetragonal $\mathrm{SnO}_{2}$ has approximately $24 \%$ crystalline $\mathrm{SnO}_{2}$ as precipitated, with a direct-band gap of $\mathrm{SnO}$ in the range of 2.1-2.4 eV and 3.4-3.8 eV for $\mathrm{SnO}_{2}$, depending on the sintering temperature. Even after sintering at $600-800{ }^{\circ} \mathrm{C}$, this sample is more disordered, with a wider Urbach tail (i.e., a higher Urbach energy), than the sample obtained by heating tin(II) oxyhydroxide at the same sintering temperature. The amorphous content and a large amount of the hydroxyl groups in the $\mathrm{SnO}_{2}$ crystals are likely contributors to the crystalline defects. The materials become less disordered and exhibit a blue-shift in absorption with increasing sintering temperature.

\section{Acknowledgment}

We thank J. Collins for technical support of the X-ray diffractometer, J. Fangmann and V. Trapp for assistance with the experiments, and F. Lamelas for helpful discussions. This work was funded in part by the National Science Foundation (CHE-0074962) and the Marquette University Committee on Research.

This article references 64 other publications.

1 Chaudhary, V. A.; Mulla, I. S.; Vijayamohanan, K.; Hegde, S. G.; Srinivas, D. J. Phys. Chem. B 2001, 105, 2565.

2Nütz, T.; Felde, U. Z.; Haase, M. J. Chem. Phys. 1999, 110, 12142.

3्Orel, B.; Lavrenćić-Štangar U.; Crnjak-Orel, Z.; Bukovec, P.; Kosec, M. J. Noncryst. Solids 1994, 167, 272.

${ }^{4}$ Dai, Z. R.; Gole, J. L.; Stout, J. D.; Wang, Z. L. J. Phys. Chem. B 2002, 106, 1274.

5Zhu, J.; Lu, Z.; Aruna, S. T.; Aurbach, D.; Gedanken, A. Chem. Mater. 2000, 12, 2557.

6Kim D.-W.; Oh, S.-G.; Lee, J.-D. Langmuir 1999, 15, 1599. 
7Ferrere, S.; Zaban, A.; Gregg, B. A. J. Phys. Chem. B 1997, 101, 4490.

${ }^{8}$ Cebolla, V. L.; Bacaud, R.; Besson, M.; Cagniant, D.; Charcosset, H.; Oberson, M. Bull. Soc. Chim. Fr. 1987, 935.

9Wang, Y.; Jiang, X.; Xia, Y. J. Am. Chem. Soc. 2003, 125, 16176.

${ }^{10}$ Robert, J. C.; Lemerle, J. I. U.S. Patent 5,401,441, 1995.

${ }^{11}$ Goebbert, C.; Aegerter, M. A.; Burgard, D.; Nass, R.; Schmidt, H. J. Mater. Chem. 1999, 9, 253.

12Hoefer, U.; Frank, J.; Fleischer, M. Sens. Actuators, B 2001, 78, 6.

$\underline{13}$ Xu, C.; Tamaki, J.; Miura, N.; Yamazoe, N. Sens. Actuators, B 1991, 3, 147.

14Zhang, G.; Liu, M. Sens. Actuators, B 2000, 69, 144.

$\underline{15}$ Xu, C.; Tamaki, J.; Miura, N.; Yamazoe, N. J. Electrochem. Soc. Jpn. 1990, $58,1143$.

$\underline{16}$ Xu, C.; Tamaki, J.; Miura, N.; Yamazoe, N. J. Mater. Sci. Lett. 1989, 8, 1092.

${ }^{17}$ Xu, C.; Tamaki, J.; Miura, N.; Yamazoe, N. J. Mater. Sci. 1992, 27, 963.

${ }^{18}$ Chiorino, A.; Ghiotti, G.; Prinetto, F.; Carotta, M. C.; Malagù, C.; Martinelli, G. Sens. Actuators, B 2001, 78, 89.

19 Ivanovskaya, M.; Bogdanov, P.; Faglia, G.; Nelli, P.; Sberveglieri, G.;

Taroni, A. Sens. Actuators, B 2001, 77, 268.

${ }^{20}$ Hahn, S. H.; Bârsan, N.; Weimar, U. Sens. Actuators, B 2001, 78, 64.

211Yamada, Y.; Yamashita, K.; Masuoka, Y.; Seno, Y. Sens. Actuators, B 2001, $77,12$.

22Pan, X. Q.; Fu, L. J. Appl. Phys. 2001, 89, 6048.

233Maekawa, T.; Tamaki, J.; Miura N.; Yamazoe, N. Chem. Lett. 1991, 575.

24 Deng, H.; Lamelas, F. J.; Hossenlopp, J. M. Chem. Mater. 2003, 15, 2429.

25 Nocuń, M. Opt. Appl. 2003, XXXIII, 183.

${ }^{26}$ Rakhshani, A. E.; Makdisi, Y.; Ramazaniyan, H. A. J. Appl. Phys. 1998, 83, 1049.

27Llosurdo, M.; Barreca, D.; Capezzuto, P.; Bruno, G.; Tondello, E. Surf. Coat. Technol. 2002, 151-152, 2.

${ }^{28}$ Demichelis, F.; Minetti-Mezzetti, E.; Smurro, V.; Tagliaferro, A.; Tresso, E. J. Phys. D: Appl. Phys. 1985, 18, 1825.

29.Melsheimer, J.; Ziegler, D. Thin Solid Films 1985, 129, 35.

${ }^{30}$ Galdikas, A.; Mironas, A.; Senulienć, D.; Šetkus, A. Thin Solid Films 1998, $323,275$.

31 Pang, G. Chen, S.; Koltypin, Y.; Zaban, A.; Feng, S.; Gedanken A. Nano Lett. 2001, 1, 723.

32Kaneko, H.; Miyake, K. J. Appl. Phys. 1982, 53, 3629.

33$V a s a n t$ Kumar, C. V. R.; Mansingh, A. J. Appl. Phys. 1989, 65, 1270.

${ }^{34}$ Steckl, A. J.; Mohammed, G. J. Appl. Phys. 1980, 51, 3890.

35Warnken, M.; Lázár, K.; Wark, M. Phys. Chem. Chem. Phys. 2001, 3, 1870.

36Altindag, Y.; Jitianu, A.; Wark, M. Stud. Surf. Sci. Catal. 2002, 141, 653. 
NOT THE PUBLISHED VERSION; this is the author's final, peer-reviewed manuscript. The published version may be accessed by following the link in the citation at the bottom of the page.

37Madan, A.; Shaw, M. P. The physics and application of amorphous semiconductors; Academic Press Inc.: San Diego, CA, 1988.

38Urbach, F. Phys. Rev. 1953, 92, 1324.

39 Kühnlenz, F.; Bark-Zollmann, S.; Stafast, H.; Triebel, W. J. Noncryst. Solids 2000, 278, 115.

40Monticone, S.; Tufeu, R.; Kanaev, A. V. J. Phys. Chem. B 1998, 102, 2854.

41Powder Diffraction File Alphabetical Indexes. Inorganic Phases; JCPDS, International Centre for Diffraction Data: Swartmore, PA, 1999.

${ }^{42}$ Cheary, R. W.; Coelho, A. A. Programs XFIT and FOURYA, deposited in CCP14 Powder Diffraction Library, Engineering and Physical Sciences Research Council, Daresbury Laboratory, Warrington, England. (http://www.ccp14.ac.uk/tutorial/xfit-95/xfit.htm), 1996.

${ }^{43}$ CRC Handbook of Chemistry and Physics, 71st ed.; Lide, D. R., Ed.; CRC Press: Boca Raton, FL, 1990/91.

44]Jenkins, R.; Synder, R. L. Introduction to X-ray powder diffractometry; Wiley: New York, 1996.

${ }^{45}$ Gauzzi, F.; Verdini, B.; Maddalena, A.; Principi, G. Inorg. Chim. Acta 1985, $104,1$.

46Lamelas, F. J.; Reid, S. A. Phys. Rev. B 1999, 60, 9347.

47Kanan, S. M.; Lu Z.; Cox, J. K.; Bernhardt, G.; Tripp, C. P. Langmuir 2002, $18,1707$.

48 Harrison, P. G.; Guest, A. J. Chem. Soc., Faraday Trans. 1 1987, 83, 3383. 499Toledo-Antonio, J. A.; Gutiérrez-Baez, R.; Sebastian, P. J.; Vázquez, A. J. Solid State Chem. 2003, 174, 241.

${ }^{50}$ Moreno, M. S.; Mercader, R. C.; Bibiloni, A. G. J. Phys.: Condens. Matter. 1992, 4, 351

51Deng, H.; Lamelas, F.; Hossenlopp, J. M. Unpublished results.

52Abrahams, I.; Grimes S. M.; Johnston, S. R.; Knowles, J. C. Acta Crystallogr. 1996, C25, 286.

53Kudo, A.; Omori, K.; Kato, H. J. Am. Chem. Soc. 1999, 121, 11459.

54Umebayashi, T.; Yamaki, T.; Itoh, H.; Asai, K. Appl. Phys. Lett. 2002, 81, 454.

55Mizoguchi, H.; Masahiro, O.; Masahiro, H.; Satoru, F.; Tomonari, T.; Hideo, H. Appl. Phys. Lett. 2002, 80, 4732.

${ }_{56}^{56}$ anga Rao, G.; Ranjan Sahu, H. Proc. Indian Acad. Sci. (Chem. Sci.) 2001, $113,651$.

57Workman, J.; Springsteen, J. A. Applied Spectroscopy: A compact Reference for Practitioners; Academic Press: San Diego, CA, 1998.

${ }^{58}$ Cabot, A.; Arbiol, A.; Ferré, R.; Morante, J. R.; Chen, F.; Liu, M. J. Appl. Phys. 2004, 95, 2178.

59Yoffe, A. D. Adv. Phys. 1993, 42, 173.

60Mastai, Y.; Polsky, R.; Koltypin, Yu.; Gedanken, A.; Hodes, G. J. Am. Chem. Soc. 1999, 121, 10047. 
NOT THE PUBLISHED VERSION; this is the author's final, peer-reviewed manuscript. The published version may be accessed by following the link in the citation at the bottom of the page.

61Navía, J. A.; Hidalgo, M. C.; Colón, G.; Botta, S. G.; Litter, M. I. Langmuir 2001, 17, 202.

62Wasim, S. M.; Rincón, C.; Marín, G.; Bocaranda, P.; Hernández, E.; Bonalde, I.; Ernesto, M. Phys. Rev. B 2001, 64, 195109.

63Giuntini, J. C.; Granier, W.; Zanchetta, J. V.; Taha, A. J. Mater. Sci. Lett. 1990, 9, 1383.

64Deng, H.; McMillan, M.; Hossenlopp, J. M. Unpublished results.

\section{Supporting Information}

Journal of Physical Chemistry B, Vol 109, No. 1 (December 2005): pg. 66-73. DOI. This article is (C) American Chemical Society and permission has been granted for this version to appear in e-Publications@Marquette. American Chemical Society does not grant permission for this article to be further copied/distributed or hosted elsewhere without the express permission from American Chemical Society. 


\section{Supporting material}

Crystalline size, band gap and Urbach energy of powders obtained from drying an aqueous $\mathrm{SnO}_{2}$ dispersion at $70^{\circ} \mathrm{C}$ and then annealing at higher temperatures.

\begin{tabular}{lccccc}
\hline Temp $\left({ }^{\circ} \mathrm{C}\right)$ & 70 & 200 & 400 & 600 & 800 \\
\hline Crystalline size $(\mathrm{nm})$ & 4.74 & 4.68 & 5.48 & 5.52 & 6.74 \\
\hline Band gap $\mathrm{E}_{\mathrm{g}}(\mathrm{eV})$ & 3.84 & 3.70 & 3.65 & 3.65 & 3.55 \\
\hline Urbach energy $\mathrm{E}_{\mathrm{u}}(\mathrm{eV})$ & 0.12 & 0.15 & 0.12 & 0.12 & 0.12 \\
\hline
\end{tabular}

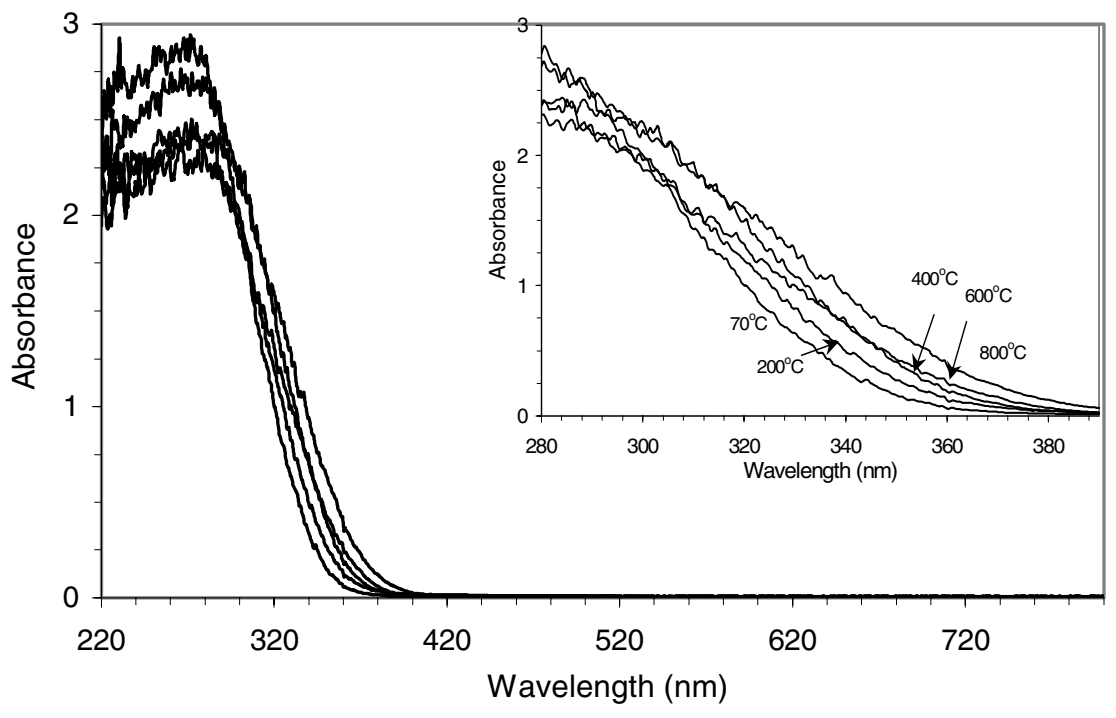




\section{Supporting material}

Crystalline size, band gap and Urbach energy of powders obtained from drying an aqueous $\mathrm{SnO}_{2}$ dispersion at $70^{\circ} \mathrm{C}$ and then annealing at higher temperatures.

\begin{tabular}{lccccc}
\hline Temp $\left({ }^{\circ} \mathrm{C}\right)$ & 70 & 200 & 400 & 600 & 800 \\
\hline Crystalline size $(\mathrm{nm})$ & 4.74 & 4.68 & 5.48 & 5.52 & 6.74 \\
\hline Band gap $\mathrm{E}_{\mathrm{g}}(\mathrm{eV})$ & 3.84 & 3.70 & 3.65 & 3.65 & 3.55 \\
\hline Urbach energy $\mathrm{E}_{\mathrm{u}}(\mathrm{eV})$ & 0.12 & 0.15 & 0.12 & 0.12 & 0.12 \\
\hline
\end{tabular}

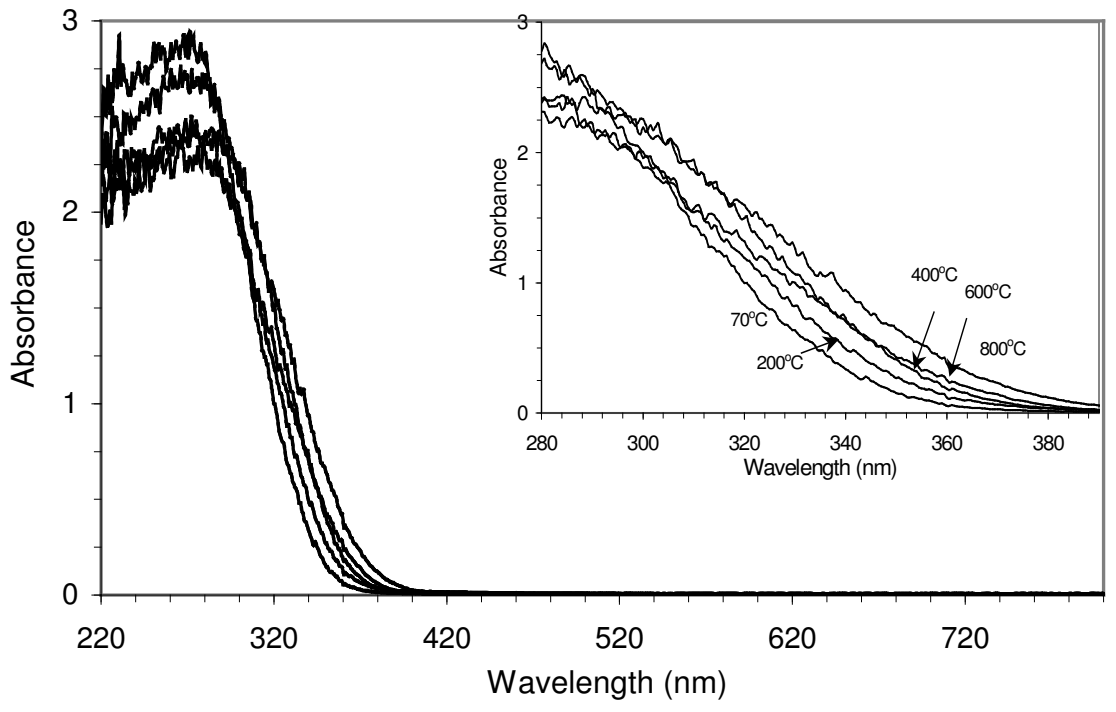

